\title{
Paget-Schroetter syndrome
}

\author{
Ardy Fenando, Mark Mujer, Manoj P Rai, Ahmad Alratroot
}

Department of Internal Medicine, Michigan State University/Sparrow Hospital, Lansing, Michigan, USA

\section{Correspondence to} Dr Ardy Fenando, ardy.fenando@hc.msu.edu

Accepted 20 October 2018

\section{DESCRIPTION}

A 21-year-old woman presented to the hospital for right lower neck pain. The patient reported that the pain started after she attempted to stretch backward. In addition, she complained of pain and swelling over her right upper arm which started a day after the neck pain started. On admission, vitals were within normal limits. Physical examination was positive for erythema, swelling and tenderness in the upper right arm and right subclavicular region. CT angiography of the neck and CT of the cervical spine were unremarkable. Complete blood count and a complete metabolic panel were within normal range. Ultrasound venous of the right upper extremity showed a large echogenic thrombus of the right subclavian vein (figure 1). Given the above findings, further detailed history was obtained. The patient denied a family history of coagulation disorder. However, she admitted to being on oral contraceptive pills. Coagulation studies showed a normal protein $\mathrm{S}$ activity along with a negative factor V Leiden, anticardiolipin and prothrombin G20210A mutation. Antithrombin III level was slightly lower. The patient was subsequently placed on a heparin infusion and was scheduled to undergo thrombolysis. Venography performed before procedure via the right basilic vein which showed complete occlusion as the axillary vein and scant collateral vessels (figure 2). The patient underwent intravenous catheter thrombolysis with $10 \mathrm{mg}$ alteplase bolus continued with $1 \mathrm{mg} /$ hour

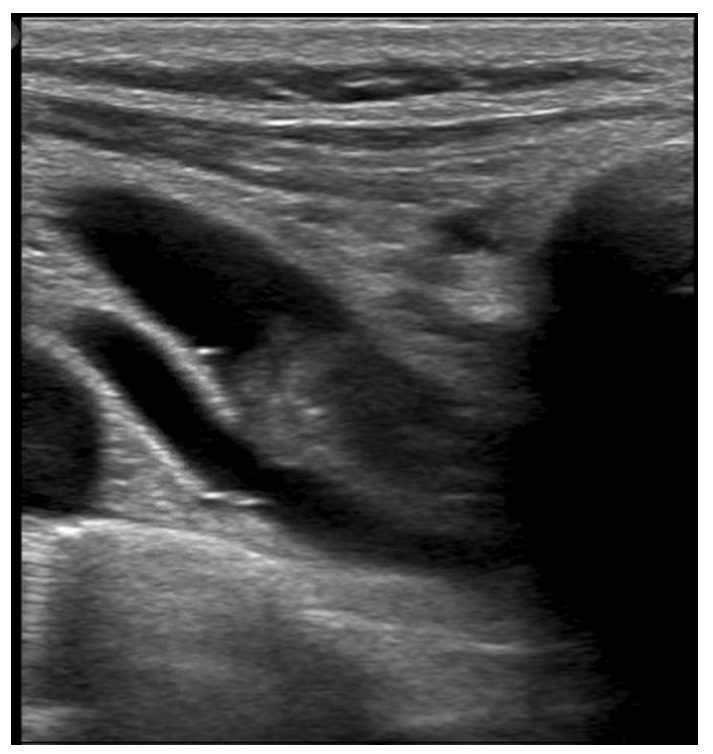

Figure 1 Ultrasound venous of the right upper extremity showing large echogenic thrombus of the right subclavian vein which appears to be moving slightly during the examination.

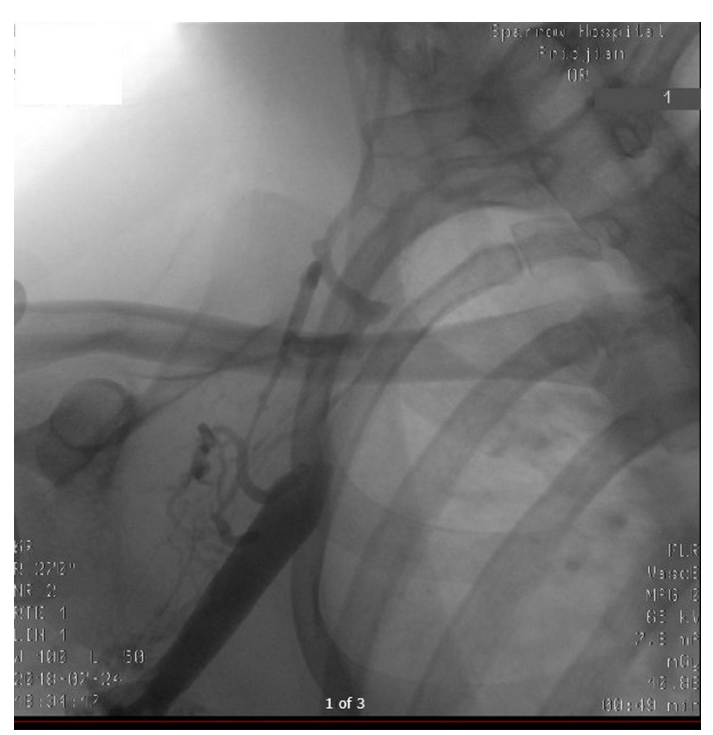

Figure 2 Venography of right upper extremity before procedure showing complete occlusion as the axillary vein entered the chest with scant collateral vessels.

intravenous infusion for 24 hours without any complications. An interval venography which was performed after a day of the procedure demonstrated a reduction in the size of the subclavian thrombus but persistent large obstructing thrombus at the first rib. There was a residual $80 \%$ obstruction that correlated with the triangle formed by the scalene anterior muscle posterior to the subclavian vein, the first rib beneath the vein and the clavicle above the vein (figure 3 ). The obstruction appeared to be complex indicative of possible residual fibrotic material or thrombus. An additional $2 \mathrm{mg}$ alteplase intracatheter bolus was given and intravenous infusion of $1 \mathrm{mg} /$ hour was restarted for another 24 hours. A $12 \mathrm{~mm}$ (length) $\times 40 \mathrm{~mm}$ (diameter) balloon angioplasty with pressure of $10 \mathrm{~atm}$ was later performed. Interval venography showed persistent $80 \%$ obstruction in the subclavian vein with good flow into a central venous system with no progression compared with the previous image findings (figure 4). No embolism following balloon angioplasty has been observed. The patient was discharged on rivaroxaban and was scheduled to undergo thoracic first rib resection in 3-4 weeks.

We considered hereditary hypercoagulability, thrombosis related to trauma or catheter placement, and thoracic outlet anatomic abnormalities (Paget-Schroetter syndrome) in our working differential diagnosis. The diagnosis of Paget-Schroetter syndrome was established given the nature of the presentation and negative hypercoagulability workup. Paget-Schroetter syndrome is characterised by primary spontaneous upper extremity deep vein 


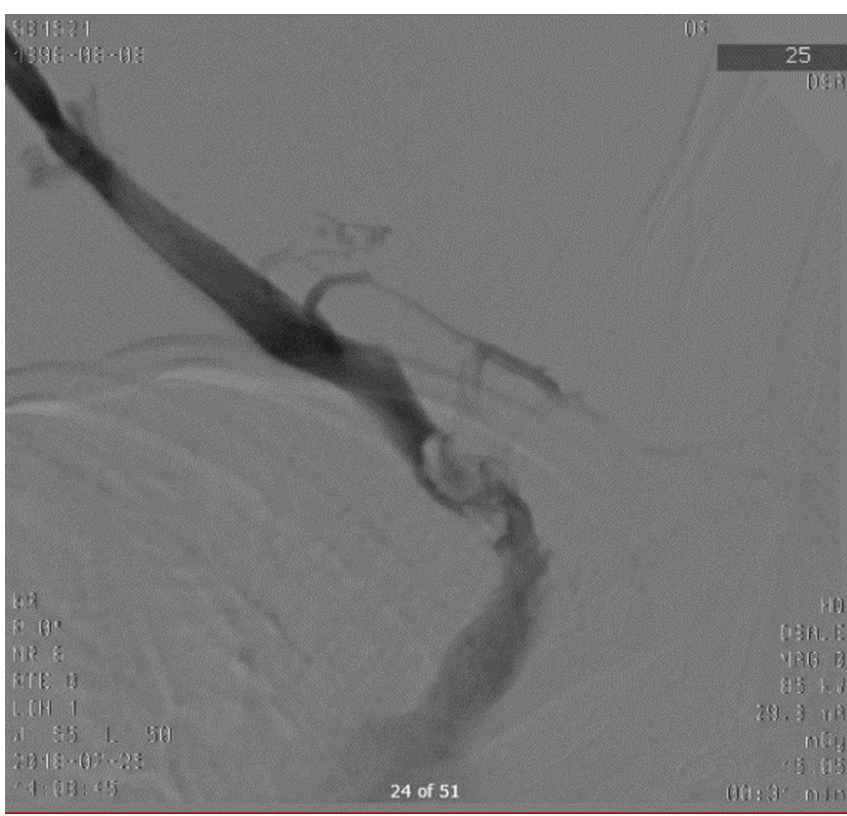

Figure 3 Venography of right upper extremity post intracatheter thrombolysis showing a large obstructing thrombus at the first rib with contrast flowing around it freely into the right atrium.

thrombosis (DVT) usually due to anatomical abnormalities of the thoracic outlet with subsequent compression of the axillosubclavian vein. ${ }^{1}$ Various structural anomalies known to cause thoracic outlet obstruction are hypertrophied muscles, cervical ribs, long transverse processes of the cervical spine, musculofascial bands and clavicular anomalies of the first rib. ${ }^{2}$ The syndrome is predominantly witnessed among young healthy individuals and it usually manifests with sudden upper extremity pain and swelling following repetitive or strenuous exercise. ${ }^{1}$ Repetitive movements of the upper extremity result in perivenous subclavian

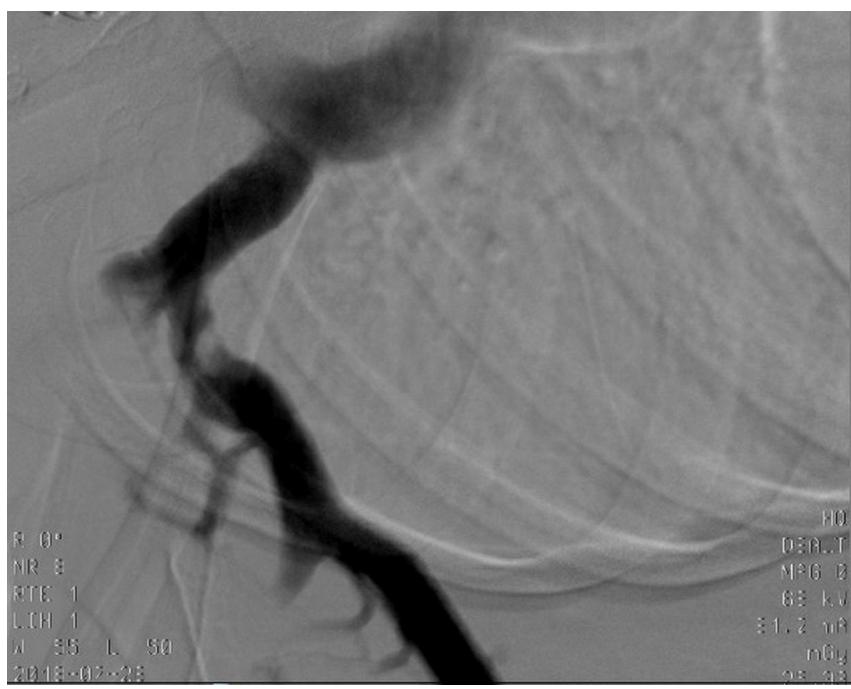

Figure 4 Venography of right upper extremity post second intracatheter thrombolysis and balloon angioplasty showing unchanged residual $80 \%$ obstruction with good flow into the central venous system. fibrosis, thus increasing the risk of thrombosis. ${ }^{3}$ There are only a few reported cases of thrombosis in the absence of the above risk factors. ${ }^{45}$ Regardless, the initial work-up should include an ultrasound to rule out the presence of a venous thrombus. A serial ultrasound or CT venography or MRI venography should be considered in cases with high suspicion for venous thrombosis even though the initial US does not show any evidence of thrombosis. ${ }^{6}$ Management goals are aimed at prevention of complications of venous thrombosis such as pulmonary embolism, recurrences and post-thrombotic symptoms. A minimum of 3 months of anticoagulation is recommended for all patients identified for upper-extremity DVT. ${ }^{7}$ For patients with moderate or severe symptoms, thrombolysis is recommended with the anticoagulation. Following thrombolysis, surgical decompression of thoracic outlet has been shown to lower rates of recurrent thrombosis and reduce long-term morbidity; however, the recommendations are very weak. ${ }^{1}$

\section{Learning points}

- The presentation of severe pain in the extremities among patients with known anatomic abnormalities should raise a high index of suspicion for Paget-Schroetter syndrome and should be worked up appropriately.

- This upper extremity thrombotic event is usually preceded by strenuous exercise or repetitive movements of the upper extremity. However, there are a few case reports which mild activities could also trigger the event.

- Thrombolysis is reserved for patients presenting with moderate to severe symptoms. Even though surgical decompression is known to lower rates of recurrent thrombosis and reduce long-term morbidity, the recommendation is weak since it is based on observational studies.

Contributors $\mathrm{AF}$ and MM wrote the primary manuscript and was revised by MPR and AA.

Funding The authors have not declared a specific grant for this research from any funding agency in the public, commercial or not-for-profit sectors.

Competing interests None declared.

Patient consent Obtained.

Provenance and peer review Not commissioned; externally peer reviewed.

\section{REFERENCES}

1 Illig KA, Doyle AJ. A comprehensive review of Paget-Schroetter syndrome. J Vasc Surg 2010;51:1538-47.

2 Goldhaber S. The A 1 and $K^{* *}$ (1320) phenomena-kinematic enhancements or mesons? Ramakrishnan A, Symposia on theoretical physics and mathematics: lectures presented at the 1966 fourth anniversary symposium of the Institute of Mathematical Sciences Madras, India. Boston, MA: Springer US, 1968:193-243.

3 Alla VM, Natarajan N, Kaushik M, et al. Paget-Schroetter syndrome: review of pathogenesis and treatment of effort thrombosis. West J Emerg Med 2010;11:358-62.

4 Taira N, Mano M, Asano H, et al. Primary subclavian venous thrombosis which developed after sleeping with the arm in an outstretched position: report of a case. Surg Today 2001;31:333-5.

5 Liang HW, Su TC, Hwang BS, et al. Effort thrombosis of the upper extremities related to an arm stretching exercise. J Formos Med Assoc 2006;105:182-6.

6 Guyatt GH, Norris SL, Schulman S, et al. Methodology for the development of antithrombotic therapy and prevention of thrombosis guidelines: antithrombotic therapy and prevention of thrombosis, 9th ed: American College of Chest Physicians evidence-based clinical practice guidelines. Chest 2012;141:53S-70.

7 Kearon C, Akl EA, Ornelas J, et al. Antithrombotic therapy for VTE disease: CHEST guideline and expert panel report. Chest 2016;149:315-52. 
Copyright 2018 BMJ Publishing Group. All rights reserved. For permission to reuse any of this content visit http://group.bmj.com/group/rights-licensing/permissions.

BMJ Case Report Fellows may re-use this article for personal use and teaching without any further permission.

Become a Fellow of BMJ Case Reports today and you can:

- Submit as many cases as you like

- Enjoy fast sympathetic peer review and rapid publication of accepted articles

Access all the published articles

Re-use any of the published material for personal use and teaching without further permission

For information on Institutional Fellowships contact consortiasales@bmjgroup.com

Visit casereports.bmj.com for more articles like this and to become a Fellow 